\title{
Comunicación

\section{La (in)visibilidad de Telesur en Argentina bajo la política de comunicación de Néstor Kirchner1}

The (in)visibility of Telesur in Argentina under the communication policies of Nestor Kirchner

GLÁUCIA DA SILVA MENDES²

El artículo presenta la investigación de por qué el gobierno de Argentina, segundo mayor accionista de la televisión multiestatal Telesur, no logró difundir la señal de la emisora en su territorio. Evidencia que el acceso limitado se debe al contexto de adición del país al canal: la política de comunicación de Néstor Kirchner, que siguió los antiguos patrones clientelistas de relación entre el Estado y los grandes grupos de comunicación.

PALABRAS ClAVE: Política de comunicación, televisión, clientelismo, gobierno Néstor Kirchner, Telesur.
This article investigates why Argentina, the second largest shareholder of the multistate television Telesur, failed to broadcast the signal of the station in its territory. It shows that the limited access is due to the context of the country's adherence to the channel: the communication policy of Nestor Kirchner, that followed the old patterns of clientelist relationship between the state and the major media groups in Argentina.

KEY WORDS: Communication policy, television, clientelism, Néstor Kirchner's government, Telesur.

1 Investigación financiada por Capes/Mincyt en el marco del proyecto binacional "Políticas de comunicación y la digitalización: nuevos modos de intervención estatal en Sudamérica. Los casos de Brasil y Argentina (20002010)".

2 Universidade Federal de Rio de Janeiro, Brasil.

Correo electrónico: gs_mendes@yahoo.com.br

Av. Pasteur 250-fundos, Urca; Río de Janeiro, Brasil. 


\section{INTRODUCCIÓN}

La emergencia de gobiernos progresistas en América Latina viene conduciendo a una estructuración más democrática en el sector de las comunicaciones en la región. Países como Venezuela, Argentina, Bolivia, Ecuador y Uruguay han adoptado medidas como la reformulación de leyes, o incentivos a la comunicación comunitaria y a la inversión en la comunicación pública y estatal.

Además de esas iniciativas de ámbito nacional, los gobiernos progresistas han invertido en cooperaciones supranacionales con el propósito de hacer frente a los conglomerados de comunicación transnacionales, que se extienden por la región difundiendo una visión unificada de los acontecimientos. Se trata de una estrategia indispensable para los nuevos tiempos:

La unión de fuerzas en escala nacional, regional y supranacional se revela indispensable para los entrechoques con los bloques hegemónicos. La defensa de la prevalencia de los intereses públicos sobre las ambiciones corporativas no puede limitarse a refuerzos dentro de cada nación: tiene que anhelar frentes supranacionales de actuación (Moraes, 2011, p. 171, traducción propia).

La pionera en ese segmento es Telesur, televisión multiestatal lanzada bajo el simbolismo del aniversario de nacimiento de Simón Bolívar, el 24 de julio de 2005. La emisora se presenta como una alternativa a las redes informativas internacionales asociadas a los grandes conglomerados multimedia (CNN, NBC, Fox News, etc.) y tiene el objetivo de posibilitar la integración entre los pueblos de la región. Ésta fue lanzada por iniciativa del presidente venezolano Hugo Chávez, con el apoyo de países como Argentina, Cuba, Uruguay, Bolivia y Ecuador.

No obstante, aunque figure como una de las mayores accionistas de la emisora, Argentina -que invirtió $20 \%$ de los recursos iniciales, después de Venezuela, responsable por $51 \%$ - no consiguió generalizar la distribución de Telesur en su territorio en los primeros años de vida del canal. El acceso se restringió a una pequeña fracción de clientes de la televisión por cable, que representa $6 \%$ del mercado potencial del 
segmento (Becerra \& Mastrini, 2009). ¿Por qué se impuso esa contradicción?, es la propuesta a investigar.

Se cree que la comprensión de este escenario requiere la observación de la política de comunicación de Néstor Kirchner relacionada con el sector televisivo. Se sustenta la hipótesis de que, no obstante el gobierno se pronunciara con la propuesta de democratización de las comunicaciones y adoptase medidas puntuales en esa dirección, su política de comunicación continuó con los patrones clientelistas que guiaron la regulación del sector en Argentina desde sus orígenes. Esa ambivalencia originó la situación de Telesur: la adhesión no se convirtió en el fortalecimiento de la emisora porque Néstor Kirchner se dejó llevar por las demandas y presiones de los grandes grupos mediáticos, contra los cuales la multiestatal afirma emprender su batalla.

Se adoptó, por tanto, como punto de partida para la investigación un constructo teórico-conceptual que busca delinear los trazos constitutivos de una política de comunicación democrática, en oposición a una política de comunicación resultante de relaciones clientelistas. Enseguida, se evidencia que a lo largo del siglo XX, las políticas volcadas para el sector de radiodifusión argentino resultaron de estrechas relaciones entre el Estado y los empresarios de comunicación, y no de debates y consenso que envolvieran a grupos sociales.

En la secuencia se buscó verificar si el gobierno de Néstor Kirchner (2003-2007), rompió o no con tales patrones. Para eso, se aclara el contexto en el cual ocurrió su ascenso a la presidencia y comienza un análisis de las acciones y omisiones que conformaron su política de comunicación en relación con el sector televisivo, evidenciando cómo ellas afectaron directa o indirectamente la difusión de la señal de Telesur en el país. Con la finalidad de posibilitar una mayor comprensión de los impactos de los dispositivos legales, se presentan datos sobre la estructuración del sector en la época de adopción de las medidas.

Teniendo en vista la baja diversidad de la televisión abierta en Argentina -en el periodo analizado, apenas siete ciudades en el interior tenían acceso a más de un canal por medio de ese servicio (Mastrini \& Marino, 2008) - y la amplia inserción de la televisión por cable en el país - prácticamente la mitad de los hogares tienen acceso a ella (Becerra \& Mastrini, 2009)-, se incluye en el análisis no solo las políticas 
relacionadas a la radiodifusión abierta, sino también aquellas relativas a la televisión pagada.

La investigación está sustentada con referencias bibliográficas especializadas en el abordaje de la política de comunicación de Néstor Kirchner y en la estructuración del sector de comunicación argentino; de la consulta y análisis de las leyes del sector vigente en el país entre 2003 y 2007, como también, de la realización de entrevistas con el representante de Telesur en Argentina.

\section{POLÍTICAS DE COMUNICACIÓN:}

¿RUMBO AL INTERÉS COLECTIVO O AL INTERÉS PRIVADO?

Como destaca Jambeiro (2000), el servicio televisivo se basa en la explotación de un bien público -el espectro radioeléctrico- y, en virtud de eso, debe ser sometido a un control por parte del Estado, con el propósito de garantizar el uso de ese bien común en pro de todos los ciudadanos. Por consiguiente, debe ser objeto de políticas públicas democráticas.

Oszlack y O’Donell (1995), conciben la política pública como un proceso social dinámico caracterizado por un conjunto de acciones u omisiones que manifiestan una determinada modalidad de intervención del Estado en relación con una cuestión que es objeto de atención, interés o movilización de la sociedad civil. Una cuestión consiste en la problematización de necesidades y demandas -que no siempre son las más importantes o urgentes en una determinada sociedad-, a partir de la perspectiva de ciertos grupos o clases.

Toda cuestión atraviesa un ciclo vital que se extiende desde su problematización hasta su resolución. En este proceso otros actores sociales afectados positiva o negativamente toman partido. Difícilmente todos los afectados coinciden en la percepción y valorización del problema social convertido en cuestión. Por consiguiente, de esta interacción social pueden resultar redefiniciones de los términos de la cuestión, de la representación y de las formas en que se agregan los actores, o bien de las resoluciones estatales que no responden al problema como fue propuesto inicialmente.

No obstante, no siempre son esos los principios que orientan las políticas de comunicación. Por envolver sujetos situados asimétricamente 
con relación en el poder, ellas pueden ser pasadas por el clientelismo, práctica caracterizada por:

Relaciones informales de intercambio recíproco y mutuamente benéfico de favores entre dos sujetos, basadas en una amistad instrumental, desigualdad, diferencia de poder y control de recursos, en las que existe un patrón y un cliente: el patrón proporciona bienes materiales, protección y acceso a recursos diversos y el cliente ofrece a cambio servicios personales, lealtad, apoyo político o votos (Cruz, 2004, p.107).

En el ámbito político, los beneficios distribuidos por el patrón en intercambio de favores con los clientes son de naturaleza colectiva: se trata de bienes abastecidos por el Estado cuyos costos son diluidos en la sociedad. El clientelismo político consiste, por tanto, en una forma de apropiación privada de lo público, que asume carácter excluyente, en la medida en que el consumo particular del bien destituye de este derecho a otros sujetos y grupos.

En un estudio comparativo que incluye países latinoamericanos, Hallin y Papathanassopoulos (2002), identifican trazos clientelistas en políticas de comunicación. Uno de ellos consiste en la conformación de cuerpos regulatorios politizados, en los cuales el poder sobre la concesión o renovación de licencias es sometido al gobierno. De esta forma se abre camino para la explotación del espectro radioeléctrico como moneda de intercambio político: la entrega de licencias se transforma en un recurso para la obtención de favores políticos.

Legislaciones con parcas restricciones a la comercialización y tenues exigencias en relación con el carácter público del servicio, también figuran como indicios clientelistas. En contextos en los cuales la radiodifusión es preponderantemente comercial, al ejemplo de América Latina, dispositivos legales como ese surgen de negociaciones en que la baja intervención en el sector es cambiada por la instrumentalización progubernamental de los medios de comunicación.

De acuerdo con Cruz (2004), el clientelismo no es sinónimo de anacronismo social. Éste no debe ser asociado a estructuras tradicionales, como una especie de práctica política residual que tiende a desaparecer con la modernización de una sociedad. Mastrini y Mastman 
(1995) evidencian la contemporaneidad de esas prácticas en la formulación de políticas de comunicación, al discurrir sobre las alteraciones legales emprendidas en el sector como resultado de la hegemonía del neoliberalismo en el mundo.

En consonancia con Murdock (1991), los autores deshacen primeramente la idea de que los cambios neoliberales resultaron en una desreglamentación, con la consecuente retirada del Estado de sus funciones. Sustentan que, al ser conducidos por el propio Estado, los recursos en términos legales deben ser entendidos como rerregulación. ${ }^{3}$ "Así, mientras se declara una supuesta apertura hacia un hipotético libre mercado, en realidad se están sentando las bases para regular en pos de una nueva estructura de propiedad cada vez más dominada por el capital concentrado" (Mastrini \& Mastman, 1995, pp. 2-3). En este proceso rerregulatorio:

Debe observarse con detenimiento, entonces, un elemento que está cada vez más presente a la hora de fijar las políticas públicas: la estrecha relación entre regulador y regulado ... que comienza con la entrada de sectores ajenos a la radiodifusión como la banca y la industria. Estos sectores poseen gran experiencia en la negociación con los respectivos gobiernos nacionales, los mejores equipos técnicos y una gran capacidad de lobby. Su influencia en la definición de políticas sectoriales es determinante y a veces superior a la de los gobiernos nacionales (p. 7).

La rerregulación neoliberal envuelve, por tanto, un compartir del poder de decisión entre regulador y regulado, hasta un límite donde lo

3 De acuerdo con Murdock (1991), la rerregulación consiste en una transformación en la base lógica del marco regulatorio de las comunicaciones que, en el neoliberalismo, se expresó principalmente en la superación del interés público por los intereses corporativos. Aun así, ella no debe ser entendida como un movimiento unidireccional, igual en el caso neoliberal. Es lo que ejemplifican las decisiones del gobierno australiano; al mismo tiempo en que relajó las reglas sobre el límite de la propiedad de emisoras de televisión, él impuso nuevas restricciones a los mismos mercados, prohibiendo la propiedad cruzada de estaciones de radio, televisión y periódicos. 
público y lo privado se tornan confusos. Produce, de esta forma, una "privatización de la función pública", en que las políticas de comunicación son definidas por un reducido grupo de actores sociales en su propio beneficio.

Una vez trazadas las características definitorias de las políticas democráticas de comunicación, en oposición a las políticas resultantes de relaciones clientelistas, cabe cuestionar: ¿cuál de esos patrones fue predominante en la elaboración de políticas de comunicación a lo largo de la historia argentina?, ¿cómo el gobierno de Néstor Kirchner se inserta en esa trayectoria? Las secciones siguientes se dedican a esos temas.

\section{RELACIONES CLIENTELISTAS Y \\ POLÍTICAS DE COMUNICACIÓN EN ARGENTINA}

La radiodifusión fue introducida en Argentina en agosto de 1920, bajo los auspicios de la iniciativa privada y la omisión del Estado. Augusti y Mastrini (2009) observaban que, en los principios de la radio, el Estado se mantuvo en una posición de espectador, dejando el desarrollo de las actividades al libre curso del mercado, sin ninguna planificación o regulación. Solamente tres años después del inicio de las transmisiones, hubo tentativas de ordenar la explotación del sector, con una propuesta de Ley de Radiocomunicaciones.

Sin embargo, en este momento el Estado enfrentó resistencia. En una primera demostración de fuerza y de capacidad de influencia en los asuntos públicos, los empresarios de la comunicación realizaron por varios días una huelga de silencio, con la finalidad de obligar al Estado a adoptar reglas de adjudicación de licencias favorables a sus intereses. El resultado fue la reelaboración del proyecto según las reivindicaciones de los empresarios y su transformación en decreto, en 1924.

Tal actitud simboliza el tipo de relaciones que se establecería entre el Estado y los propietarios de medios a lo largo de todo el siglo XX.

En una actuación premonitoria del comportamiento del Estado a lo largo del siglo XX, los gobiernos se limitaron a convalidar la iniciativa asumida por el sector privado. Ya en la década del 30, se afirma una creciente relación entre los propietarios de medios y los diferentes gobiernos mediante la cual estos 
últimos no entorpecen el desarrollo de las empresas, a cambio de ciertos límites en los contenidos políticos y en las críticas al gobierno (Augusti \& Mastrini, 2009, p. 54).

La tónica clientelista del decreto volcado para la actividad radiofónica se repitió en la elaboración de la Ley de Servicios de Radiodifusión de 1953, núm. 14.241, primera ley general del sector en Argentina. Propuesta y sancionada bajo el gobierno de Perón, la normativa delegó al Poder Ejecutivo la prerrogativa de conceder a particulares la autorización para la prestación de los servicios. Según Arribá (2009), la ley abrió camino para la conformación de un sistema de radiodifusión "paraestatal", con la entrega de medios de comunicación a personas próximas a Perón, y la consecuente explotación de las licencias en consonancia con los propósitos políticos del gobierno.

Mas las estrechas relaciones entre regulador y regulado en la elaboración de las políticas de comunicación no fueron una marca apenas de las primeras décadas de la radiodifusión. Como evidencian Marino y Postolsky (2009), también el decreto-ley 22.285, de 1980 -gestado en la dictadura y vigente hasta el año 2009-, nació de negociaciones de esa naturaleza. La norma fue elaborada por funcionarios del Poder Ejecutivo con el asesoramiento de las principales asociaciones patronales del sector. Como consecuencia, la legislación asumió un carácter autoritario y privatista, negando a todos los actores sin fines de lucro la posibilidad de dirigir medios de comunicación.

El decreto-ley de la dictadura sentó la base para la emergencia y la consolidación de la hegemonía del neoliberalismo en el sector de comunicación argentino, promovidas especialmente por los gobiernos de Carlos Menem, a partir de 1989. Sin embargo, como parte de un proceso que, según Rossi (2009), fue marcado por un permanente lobby de las asociaciones empresariales, la norma todavía fue readecuada para posibilitar la concentración multimedia y la internacionalización del sector.

Poco después de asumir la presidencia, Menem promovió la primera rerregulación neoliberal. Por intermedio de la Ley de Reforma del Estado, núm. 23.696/89, flexibilizó el decreto-ley para permitir la constitución de conglomerados multimedia eliminando, por ejemplo, 
las restricciones relativas al número de licencias de radio y televisión en las manos de una misma persona física o jurídica, a la propiedad cruzada y a la constitución de sociedades de personas jurídicas para dirigir los medios de comunicación.

Una nueva regulación fue realizada con la finalidad de posibilitar la entrada del capital externo en el sector. De acuerdo con Marino (2007), las inversiones extranjeras obtuvieron estatus legal con la firma del Tratado de Promoción y Protección de Inversiones entre Argentina y Estados Unidos, en 1991, y su validación con la Reforma Constitucional de 1994, que concedió primacía a los acuerdos internacionales, en detrimento de las leyes argentinas.

En los últimos días de su mandato, en 1999, Menem también sancionó el decreto núm. 1.005/1999, legalizando varios aspectos asumidos por los oligopolios transnacionales al margen de la legislación vigente. De entre las formalizaciones realizadas, Albornoz y Hernández (2009), destacan: la autorización de ingresos de capital extranjero de otros países que firmaron Tratados de Reciprocidad con Argentina además de Estados Unidos; la ampliación del número de licencias por operadores de 4 a 24; la autorización de cadenas permanentes de transmisión y autorización para la transferencia de licencias, facilitando así la compra y venta de medios.

No fue otra la marca que Fernando De la Rúa imprimió a su política de comunicación, al asumir la presidencia en diciembre de 1999:

El análisis de la intervención del gobierno en el área permite poner de manifiesto quienes fueron los verdaderos reguladores y rerreguladores de la radiodifusión durante este período: los grupos poderosos de la comunicación encabezados por los hegemónicos Telefónica y Clarín ... no se modificó la cercanía entre regulador y regulado, sino que parece instalarse con la naturalidad con que el lobbying de las empresas y grupos poderosos del sector se apropia de los organismos reguladores y privatiza la función pública para la consecución de sus objetivos (Leiva, 2009, pp. 308-309).

De entre las regulaciones viradas para atender los intereses de los empresarios de comunicación figura la aprobación de la reforma del Código Penal, en 2001, con el propósito de castigar las emisiones clan- 
destinas de radio y televisión e imponer sanciones a sus responsables. También fue resultado del trabajo de los lobbistas la edición del decreto núm. 1522/01, que redujo los pagos al Estado por los concesionarios de los servicios de radiodifusión.

La política de comunicación de Fernando De la Rúa fue prematuramente interrumpida por un cuadro de inestabilidad económico/social que anunciaba la crisis de la hegemonía neoliberal y conduciría al estruendo de la mayor crisis económica del país. Delante de la caótica situación que se instaló en la sociedad argentina en ese momento, De la Rúa anunció oficialmente su renuncia a la presidencia el 19 de diciembre de 2001.

¿Qué impactos produjeron esos acontecimientos sobre los rumbos de las políticas de comunicación argentinas?, ¿ellos representarían una ruptura con los patrones que venían siendo observados en la conducción del sector? Para responder a estas interrogantes se hace necesario seguir los desdoblamientos políticos del desafortunado diciembre de 2001 .

\section{ASCENSIÓN Y AMBIVALENCIA \\ DEL GOBIERNO DE NÉSTOR KIRCHNER}

Conforme plantea Califano (2007), los acontecimientos que culminaron con la renuncia de Fernando De la Rúa fueron motivados por la creciente inestabilidad de la moneda argentina y la consecuente carrera a los bancos para la retirada de depósitos. Con la finalidad de evitar la quiebra del sistema financiero y salvaguardar a las entidades bancarias, el gobierno impuso entonces drásticas restricciones a la extracción de fondos, estableciendo lo que se conoció como "corralito". La medida, anunciada junto con la declaración de estado de sitio, exaltó los ánimos y generó una onda de saqueos, movilizaciones y enfrentamientos que dejaron un saldo de 34 muertos en todo el país. El clima social y la pérdida de apoyo político no dejaron a De la Rúa otra alternativa que renunciar.

Lejos de resolverse con ese acto, el cuadro económico/político/social se agravó todavía más, culminando con la mayor crisis de la historia en el país. En 12 días, Argentina fue conducida por cinco presidentes diferentes, hasta la ascensión interina de Eduardo Duhalde, en enero de 2002. La decisión del nuevo presidente de desvalorizar la moneda puso 
fin a la equiparación entre el peso y el dólar establecida por Carlos Menem en la década de 1990 (conocida como convertibilidad) y tornó la situación más trágica; el país se sumergió en una de sus mayores recesiones, alcanzando un nivel récord de pobreza ( $57.5 \%$ de la población) y un aumento considerable de los índices de desempleo.

El gobierno tuvo entonces que enfrentar la presión de los actores económicos perjudicados por la desvalorización de la moneda. Baladrón (2009), considera que los medios de comunicación asumieron un papel central en ese proceso, en función de su doble condición; de actores económicos y de formadores de opinión. El principal lobby de los empresarios de comunicación fue por una medida que los eximiese de la modificación de la Ley de Quiebras, exigida por el Fondo Monetario Internacional (FMI) con el propósito de permitir a los acreedores externos cancelar la deuda con la apropiación de acciones de las empresas deudoras.

El resultado fue la redacción de la Ley de Preservación de Bienes y Patrimonios Culturales, núm. 25.750, cuyo breve texto se limitaba a los medios de comunicación, a pesar de que el título indicaba un propósito más amplio. La norma estableció un límite de 30\% para el capital extranjero en la propiedad de medios de comunicación-excepto para aquellos que ya estaban en manos extranjeras o que celebraron contratos antes de la ley-, impidiendo la extranjerización total de las empresas. Aunque hubiera sido sancionada en el gobierno Duhalde, la simple elaboración de la ley evidenció la fuerza política de los grandes propietarios del sector.

En plena crisis institucional y económica, los actores más poderosos demostraron una vez más que siguen siendo los únicos que deciden sobre radiodifusión. Los medios de comunicación fueron el único sector empresario que obtuvo una legislación específica para resguardar su propiedad luego de que se restituyera el mecanismo de cram down, con la segunda modificación de la Ley de Quiebras ... La política pública sobre radiodifusión parece haber tenido como único propósito la defensa de los medios nacionales en tanto empresas, pero sin contemplar como contraparte ninguna exigencia para incentivar el sector. Los límites de la protección quedaron restringidos a un tema de propiedad, y tampoco pudieron implementarse cambios que fueran en contradicción con los intereses de empresa (Baladrón, 2009, p. 330). 
El agravante cuadro económico también impulsó movilizaciones sociales, en las cuales el pueblo demostraba su insatisfacción con los rumbos políticos del país. Una de ellas precipitaría nuevamente los acontecimientos políticos; la manifestación que reunió diversas agrupaciones piqueteras en el puente Pueyrredón, el 26 de junio de 2002. El episodio, conocido como "Masacre de Avellaneda", fue marcado por la represión policial y tuvo como saldo dos muertos y varios heridos. La responsabilidad del gobierno en relación con las muertes apresuró el llamado a elecciones presidenciales para abril de 2003.

En este contexto de convulsión social y crisis económica surgió como candidato apoyado por Duhalde un personaje político hasta entonces desconocido nacionalmente: Néstor Kirchner. Aunque figurase en las encuestas como la última opción de los argentinos, Kirchner se quedó en segundo lugar en la primera vuelta, alcanzando $22.24 \%$ de los votos, atrás apenas de Carlos Menem, con un 24.45\%. En la preparación para la segunda vuelta, se volvió mandatario de la nación ante la inesperada renuncia de Carlos Menem.

Néstor Kirchner llegó así a la Presidencia de la Nación con el porcentaje de votos más bajo en la historia argentina. Califano (2007), considera que tal hecho le impuso la necesidad de ampliar su base de sustentación. Para eso, sería necesario producir a corto plazo alteraciones significativas en el delicado cuadro argentino, alcanzando tanto éxitos económicos como sociales. También sería fundamental en esta tarea el apoyo de la opinión pública, que inevitablemente dependería de la actuación de los grandes medios de comunicación.

Frente al desafío impuesto, el gobierno de Néstor Kirchner adquirió un carácter ambivalente. Al mismo tiempo en que sustentó un discurso de confrontación del modelo neoliberal, no pudo prescindir totalmente de sus prácticas para alcanzar los resultados económicos esperados. La administración kirchnerista puede ser encuadrada en la clasificación presentada por Moraes (2011) 4 con el objetivo de evaluar las transfor-

4 Según Moraes es posible distinguir dos bloques de gobierno en América Latina: el primero es constituido por los países que hacen parte de la Alianza Bolivariana de las Américas (ALBA) y priorizan agendas y sociedades que viabilicen el desarrollo sustentable y promuevan la integración económica 
maciones políticas vividas por América Latina en el último decenio, en el bloque de países cuyas políticas oscilan entre la defensa de la inclusión social y la adopción de medidas económicas favorables a los intereses del mercado.

Se trata, por lo tanto, de un gobierno marcado por contradicciones. Éstas son observadas, por ejemplo, en el sector de comunicaciones, en el cual Postolsky (2010), afirma que las amenazas a los grandes conglomerados y las promesas de democratización realizadas por Kirchner en el nivel discursivo no coincidían con las prácticas de favorecimiento hacia éstos. Dichas prácticas se tornaron perceptibles desde el inicio de la administración; conforme relata Califano (2007), menos de un mes después de la toma de posesión de la presidencia, Kirchner sancionó la ley núm. 25.750/03, de "Preservación de Bienes y Patrimonios Culturales", gestada en la administración de Duhalde.

La postura favorable a los grandes grupos del sector se confirmó en los años subsiguientes, plasmándose en otras decisiones. Entre ellas, se destaca la renovación automática de las licencias de los principales canales de televisión abierta del país. De acuerdo con Califano (2007), en las vísperas del vencimiento de las concesiones, cuya expiración estaba prevista para el inicio de 2005, el gobierno firmó las resoluciones núms. 1.326/04 y 1.837/04, que extendieron 10 años más (hasta 2015) las licencias de los canales 11 y 13 de Buenos Aires, respectivamente.

Mientras tanto, Kirchner también impuso medidas que, al menos a primera vista, pueden ser consideradas importantes para la democratización de las comunicaciones. Se incluye en este rol la sanción de la ley núm. 26.053/05, que puso fin a la barrera para la adjudicación de licencias de radiodifusión a las personas físicas y jurídicas sin fines lucrativos, instituida por el Decreto-Ley de Radiodifusión. No obstante, un análisis atento revela serias limitaciones a su aplicación práctica: mantuvo fuera a las cooperativas de servicio público, las únicas entidades con capacidad económica para hacer frente al poder de los conglomerados comunicacionales.

y cultural regional; el segundo, formados por Brasil, Uruguay, Argentina y Chile, oscila entre la defensa de la inclusión social de clases más pobres y políticas económicas favorables al mercado. 
Además de eso, la ley tuvo su efecto anulado por llegar tres meses después la reiteración del status quo promovida por el decreto núm. $527 / 05$, que suspendió por 10 años la cuenta del plazo de validez de las licencias de todos los medios de comunicación. Por fin, como destacan Mastrini y Marino (2008), la ley no nació de un plan estratégico del gobierno, derivó de una decisión jurídica que señaló la inconstitucionalidad de la exclusión instituida por la ley de la dictadura.

A continuación se argumenta que la adhesión a la emisora latinoamericana Telesur se trató de otra medida cuyos efectos prácticos fueron casi nulos en el gobierno de Néstor Kirchner, en función de las mencionadas continuidades en términos de política de comunicación. Aunque Argentina se ha vuelto copropietaria del medio, su señal llegó a pocos hogares, debido a la manutención y/o adopción de políticas benéficas a los conglomerados multimedia.

\section{TELESUR (¿) LlEGA (?) A ARGENTINA}

En el aire desde el 24 de julio de 2005, aniversario del nacimiento de Simón Bolívar, Telesur surgió como una iniciativa del gobierno de Venezuela (con $51 \%$ de sus acciones), inicialmente apoyada por los mandatarios de Argentina (20\%), Cuba (19\%) y Uruguay (10\%). ${ }^{5}$ Con el eslogan "Nuestro Norte es el Sur", la emisora se propone ser una alternativa frente a las redes informativas internacionales vinculadas con los conglomerados (CNN, NBC, Fox New, etc.), que promueva la integración entre los países latinoamericanos, concediéndoles espacio para divulgar su propia imagen y transmitir sus propios contenidos (Moraes, 2011).

La orientación del vehículo es esencialmente informativa. Aproximadamente $80 \%$ de su contenido es periodístico; $20 \%$ restante está compuesto por películas y documentales independientes producidos en la región, muchos exhibidos por primera vez. En la barra de programación se destacan los telediarios, transmitidos cada hora, programas

5 Con el pasar de los años y la elección de gobernantes simpatizantes a las políticas chavistas, otros países se transformaron en accionistas del canal: Bolivia (2006), Ecuador (2006) y Nicaragua (2007). 
como "Reportaje Telesur" con temas de investigación sobre asuntos de impacto en la región; "Maestra vida", dedicado a la biografía de personajes populares y figuras destacadas de América Latina, y "Vamos a conocernos", enfocado en la diversidad cultural.

La composición accionaria del canal levanta cuestionamientos sobre hasta dónde va la participación latinoamericana. La posesión de más de la mitad de las acciones por el Estado venezolano le confiere un poder de decisión que prácticamente no deja márgen de interferencia en los rumbos de la emisora. El país designa al directorio ejecutivo y, para críticos, ejerce influencia en la línea editorial. En la visión de Omar Rincón (Moraes, 2011), aunque sea una idea necesaria al continente, Telesur no representa a América Latina, sino apenas al pensamiento chavista.

Además de la discusión sobre la autonomía o no del vehículo en términos políticos -que se refiere a prácticamente todos los medios estatales latinoamericanos, ya que la región es una de las únicas del mundo donde la noción de servicio público de comunicación no prosperó (Becerra, 2010)-, creemos que es esencial observar si Telesur de hecho cumple su objetivo de ser un medio de comunicación latinoamericano, no solo en términos de los contenidos que exhibe, sino también de la pretensión en la difusión de su señal por el subcontinente.

Con el foco en el segundo aspecto, analizamos la situación de Telesur en Argentina. Además de ser el segundo mayor accionista del canal, el país fue uno de los primeros en adherirse a la iniciativa el 1 de febrero de 2005. Antes del lanzamiento de la emisora, Kirchner y Chávez subscribieron un convenio de fortalecimiento de la Nueva Televisora Del Sur S.A. (Telesur) ("Presidentes Chávez y Kirchner suscribieron acuerdos de cooperación e integración”, 2005). En el documento se comprometieron con:

El intercambio de recursos técnicos y humanos, de conformidad con las legislaciones internas y compromisos internacionales de ambos países, a los fines de promover el fortalecimiento de la nueva Televisora del Sur S. A. (TELESUR), (Flores, 2005).

A pesar de adherirse a la emisora, el gobierno de Néstor Kirchner no universalizó el acceso a su señal en territorio argentino. De acuerdo 
con el suplente de la delegación argentina en la dirección de Telesur, Néstor Piccone (Califano, 2007), solamente los clientes del servicio de televisión por satélite DirecTV obtuvieron acceso a la programación del canal durante la gestión de Kirchner. Lo que, en términos de público potencial, representaba un promedio de $6 \%$ de los telespectadores del país (Becerra \& Mastrini, 2009), ¿cómo explicar esa contradicción?

Se cree que ella debe ser comprendida a la luz de la política de comunicación de Néstor Kirchner direccionada para el sector televisivo. Se sustenta que la limitación del acceso a la multiestatal deriva de una política basada en relaciones clientelistas entre el Estado y los propietarios del medio. Aunque se refiriese con la propuesta de democratización de las comunicaciones y adoptase medidas puntuales en esa dirección, el gobierno continuó guiando sus decisiones por las demandas y presiones de los grandes grupos mediáticos, contra los cuales Telesur entabla su batalla.

En este sentido, se debe destacar en primer lugar que la firma del convenio bilateral de fortalecimiento de Telesur fue realizada bajo una legislación que reservaba las licencias al sector comercial. La manutención en vigor del decreto-ley núm. 22.285/80, de trazos privados, indicó la presencia de un modelo que privilegiaba la explotación de la actividad para fines de lucro. La norma delegaba incluso un papel secundario a los medios públicos de comunicación, restringiendo la actuación de éstos a las áreas donde el servicio de radiodifusión no fuera prestado por el sector privado. De acuerdo con el artículo 10:

El Estado Nacional promoverá y proveerá servicios de radiodifusión cuando no los preste la actividad privada, en zonas de fomento y en las zonas de frontera, especialmente en las áreas de frontera, con el objeto de asegurar la cobertura máxima del territorio argentino (Ley núm. 22.285, 1980).

Aunque el expresidente Eduardo Duhalde hubiera editado en 2002 el decreto núm. 2368/02, con el propósito de poner fin a la subsidiariedad del Estado en la radiodifusión, éste solo fue validado por el Congreso en los últimos meses de la administración de Néstor Kirchner, en septiembre de 2007. En dicho intervalo, cualquier tentativa de concurrencia del Estado con la iniciativa privada sería impedida por ilegal, como ocurrió en la ciudad de San Rafael, donde la transmisión del Canal 7 fue prohibida por 
una acción interpuesta por TV Río Diamante, propiedad del conglomerado Vila-Manzano, que actuaba en el mercado local6 (Califano, 2007).

De esta forma, la propuesta de Telesur se quedaba comprometida. Como se mencionó, la emisora anhelaba establecerse como una alternativa al discurso periodístico difundido por los conglomerados mediáticos, lo que presupone justamente la concurrencia, la ocupación de los espacios dominados por el medio privado, para tornar viable esa disputa simbólica.

Así como los presidentes que lo antecedieron, Kirchner se desligó de la responsabilidad de poner fin a la pesada herencia dictatorial, promulgando una ley de comunicaciones que estuviese calzada en principios democráticos. Ésta fue una de sus promesas de mandato que no prosperó, aunque haya ganado terreno en la sociedad civil un movimiento que la respaldaba y presionaba por su concretización; la Coalición por una Radiodifusión Democrática.

Constituida a inicios de 2004, a partir de la unión de actores sociales diversos que tras la dictadura luchaban aisladamente por la elaboración de una ley de comunicaciones democráticas, la Coalición redactó un documento conteniendo lo que consideraba serían principios fundamentales de una nueva ley para el sector. Titulado "21 Puntos Básicos por el Derecho a la Comunicación", reunía 21 directrices - una para cada año democrático transcurrido hasta entonces-, que surgieron del consenso entre diversos segmentos sociales (Busso \& Jaimes, 2011).

Dentro de los principios catalogados por el documento, consta una orientación que podría revertir la situación de los medios de comunicación estatales. El texto reconoce la existencia de tres tipos de prestadores de servicios de radiodifusión - públicos, comerciales y comunitarios de organizaciones de la sociedad civil sin fines de lucro-y propone la eliminación de cualquier discriminación o cercenamiento en función de la naturaleza jurídica de la organización propietaria, incluso en lo que concierne a la potencia y a la cantidad de frecuencias disponibles.

Con los 21 puntos en manos, todavía en 2004 el grupo se reunió con representantes del gobierno, proponiendo su involucramiento con

6 Después de la validación del decreto por el Congreso, la medida cautelar fue revocada y la señal de la emisora estatal restituida. 
la causa. En este primer encuentro, hubo el reconocimiento de que una nueva ley era una deuda pendiente de la democracia, mas se argumentó que la correlación de fuerzas impedía incluir el tema en la agenda oficial. La Coalición tomó otros caminos: interpeló al Poder Legislativo, y fue recibida por representantes de la Cámara de los Diputados y del Senado. Aún así, poco se avanzó en ese momento.

Por el contrario, el movimiento sufrió una inflexión en el año siguiente, con una rerregulación proconglomerados: el decreto núm. 527/05.

La firma del Decreto $\mathrm{N}^{\circ} 527$ fue un momento difícil para la Coalición, donde se tornó complicado sostener la militancia y, especialmente, la esperanza. Era una señal de lo difícil que sería avanzar con un proyecto de ley que pudiera remplazar la ley de la dictadura vigente porque al gobierno que tomara una iniciativa como esta, le costaría la enemistad de los grupos mediáticos (Busso \& Jaimes, 2011, p. 52).

El decreto suspendió el recuento del plazo de validad de las licencias de radiodifusión por 10 años. De esta forma, todos los licenciatarios (que, por la ley, eran de naturaleza comercial), contaron con el amparo legal para perpetuarse en la explotación del espectro radioeléctrico (Califano, 2007). Los canales 11 y 13 de Buenos Aires (dirigidos por conglomerados multimedia), que poco antes habían obtenido la renovación automática de sus licencias, vieron su vida prolongada por 20 años.

De acuerdo con Postolsky (2010), la medida fue resultado de una negociación del presidente con el sector mediático, a cambio de apoyo político en las elecciones de 2005. La disputa central en el pleito giraba en torno de la elección de senador en la provincia de Buenos Aires, que tenía como una de las postulantes al cargo a la esposa del presidente, Cristina Fernández de Kirchner.

La alianza con el sector mediático resultó central para lograr aquel triunfo (de Cristina) electoral que proyectó al entonces presidente Néstor Kirchner como el político más poderoso del país” (Postolsky, 2010, p. 145).

Para entender la dimensión de los efectos de la norma, se debe retomar una medida menemista: la privatización de la banda UHF. Como 
recuerda Rossi (2009), en el primer gobierno de Menem (1989-1995), las frecuencias UHF, nunca antes explotadas comercialmente, fueron agotadas al ser entregadas prácticamente en paquetes para la iniciativa privada. La adjudicación de licencias ocurrió sin planificación y sin la necesaria llamada a concurso. Según Albornoz y Hernández (2009), en muchos casos fueron entregadas a los grupos propietarios de los canales de televisión abierta más importantes del país.

Por tanto, a la restricción impuesta a los medios de comunicación estatales por el decreto-ley venía a sumarse una decisión que provocaba una limitación de orden técnica. La indisponibilidad de espacio en el espectro radioeléctrico, reiterada por el decreto, inviabilizó la posibilidad de transmisión de Telesur en red abierta y gratuita, que garantizaría equidad a los ciudadanos argentinos en el acceso al contenido de la emisora. Al contrario, favoreció justamente los grupos concentrados que la emisora pretende combatir.

Si en la radiodifusión abierta el canal no obtuvo espacio, tampoco el segmento de televisión por cable -que a la época alcanzaba más de $50 \%$ de los hogares argentinos (Becerra \& Mastrini, 2009)- le abrió las puertas. A pesar de ser una señal gratuita que no representaría costos adicionales de distribución, los operadores de cable se negaron a incluir la emisora en su barra de programación. Según Esteban (2011), la justificación presentada era la inexistencia de espacios para incorporar la señal, sin embargo otras razones pueden ser consideradas.

Para eso, es necesario observar la estructura del segmento heredada por Néstor Kirchner, que se conformó especialmente a lo largo de los gobiernos menemistas. La apertura del camino a los procesos de concentración y extranjerización en la década de los noventa impulsó la compra, por las mayores compañías, de pequeños operadores de televisión por cable del interior, conduciendo al predominio en el sector de dos empresas que contaban con participación accionaria extranjera: Cablevisión y Multicanal (Marino, 2007). Para forzar las ventas, los grandes operadores se valían de dos armas adicionales: el control de las principales señales de televisión que integraban la barra de los pequeños y la posesión de los derechos de transmisión de las partidas de futbol.

La extranjerización del servicio se reveló no solo en la propiedad de los medios, sino también en la provisión de señales. Ésta se llevó a cabo 
por un reducido grupo de empresas, controladas por los mismos conglomerados globales que integran el capital de las operadoras de cable. Como ejemplifica Marino (2007), las señales distribuidas por Liberty Media y HMT\&F, accionistas de Cablevisión, correspondían a 43\% de la barra del operador, por lo tanto, los principales operadores del sistema se encontraban asociados a los principales proveedores de señales, por intermedio de concentración vertical.

Krakowiak (citado en Marino, 2007), resalta que el control sobre diferentes fases del sistema puede llevar a las empresas a utilizar su posición dominante en el mercado para excluir señales competidoras. Se argumenta que ese es el caso de Telesur. La emisora se presenta como una alternativa a las cadenas informativas internacionales, especialmente a CNN en español, entonces controlada por Time Warner, empresa que figuraba como accionista de los principales operadores del sistema de televisión por cable argentino (Marino, 2007).

Es importante destacar que esa estrategia de dominación del mercado puede afectar el sistema como un todo y no solo a los grupos concentrados. Como recuerda Marino (2007), el control sobre un insumo básico (en el caso, las principales señales televisivas) otorga a los conglomerados un poder de presión. Por esta razón, se sustenta que la ausencia de Telesur no solo de la barra de programación de Cablevisión y Multicanal, sino también de los pequeños operadores esté relacionada a la concentración vertical de la televisión por cable argentina.

También en el sector de televisión por cable el gobierno de Néstor Kirchner tomó decisiones que favorecieron a los grandes grupos de comunicación, dificultando el camino para la difusión de Telesur. Una de ellas fue la manutención de la suspensión de licitaciones para la prestación del servicio. Como explica Califano (2007), la medida, adoptada por primera vez en el año 2000, en el gobierno de Eduardo Duhalde, tenía como propósito inicial ayudar a los principales operadores a enfrentar la crisis económica provocada por la desvalorización de la moneda argentina, impidiendo la entrada de nuevos actores en el sistema.

A partir de entonces, fueron dictadas sucesivamente resoluciones para renovar la suspensión, a pesar de las sentencias judiciales que las declararan inconstitucionales. En 2006, Néstor Kirchner la reiteró, estableciendo la condición de que la licitación solo ocurriría cuando fuera 
aprobada la "Regulación para el acceso a las licencias y prestaciones de los servicios complementares de radiodifusión". Mientras tanto, hasta el fin de su mandato éste no había sido redactado (Califano, 2007). El resultado fue la exclusión de potenciales concurrentes, cuya presencia podía llevar a la pluralización del sistema, con la transmisión de señales alternativas.

En el apagar de las luces de su mandato, Néstor Kirchner tomó una decisión que condujo al sector a una situación casi monopólica. Se encontraba pendiente para análisis en la Comisión Nacional de Defensa de la Concurrencia, órgano del Ministerio de la Economía, la fusión de los mayores operadores de televisión por cable del país -Cablevisión y Multicanal-, bajo el control del Grupo Clarín. El 7 de diciembre de 2007, tres días antes de pasar la franja presidencial a su esposa, Kirchner aprobó la fusión. El nuevo grupo concentró 55\% del mercado de televisión por cable del país y $85 \%$ del acceso en los hogares de la capital federal (Califano, 2007).

Por lo tanto, Néstor Kirchner solo contribuyó para tornar todavía más concentrado un sector en que es grande el poder de los conglomerados para decidir qué señales incluir o excluir de todo el sistema. Emprendió más un conjunto de prácticas que neutralizaron los efectos que podrían advenir de la adición de Argentina a la multiestatal Telesur.

\section{CONSIDERACIONES FINALES}

La asunción de Néstor Kirchner a la presidencia de Argentina en medio de una crisis económica de grandes proporciones y las reivindicaciones populares por la alteración de los rumbos políticos del país produjeron señales inciertas en su administración. Al mismo tiempo en que se proponía abandonar el modelo neoliberal vigente, el gobernante no pudo prescindir totalmente de las prácticas de éste para obtener los resultados económicos esperados.

Esta ambivalencia se hizo sentir en el sector de comunicación, en el cual las promesas de democratización contrastaron con antiguas prácticas clientelistas. En vez de fomentar debates en la sociedad civil para la formulación de políticas democráticas de comunicación -como lo iniciado por la Coalición por una Radiodifusión Democrática, con la 
intención de elaborar una nueva ley de radiodifusión-, el presidente continuó negociando los dispositivos legales directamente con los grandes grupos del sector.

Los límites impuestos a la difusión de Telesur en Argentina derivan de tal escenario. La persistencia de un marco legal privativo -en el cual los medios de comunicación estatales eran relegados a una función subsidiaria-, asociada al decreto núm. 527/05 -que garantizó la perpetuación de los agentes privados que ya explotaban hace años el servicio de radiodifusión- y al cuadro de agotamiento de frecuencias, cerraron las posibilidades de difusión de la emisora en señal abierta.

En el mercado de televisión por cable, concentrado no solo horizontalmente, sino también verticalmente, la emisora tampoco consiguió espacio. La intrincada relación entre los mayores operadores del servicio y los proveedores de las señales a los cuales Telesur se opone condujo a la exclusión de la multiestatal, no solo de los paquetes de los conglomerados del sector, sino también de todo el sistema, dada la presión ejercida por los grandes sobre los pequeños operadores incluso en términos de programación.

El gobierno de Néstor Kirchner solamente intensificó el cuadro conglomeral que producía tales efectos. Al adoptar medidas como la manutención de la suspensión de la llamada a licitaciones y la aprobación de la fusión entre Multicanal y Cablevisión, contribuyó para tornar el sector todavía más concentrado y, por extensión, amplió el poder de decisión de los grandes grupos sobre las señales a incluir o no en el sistema.

No obstante, la política de comunicación kirchnerista no se agotó con la salida de Néstor Kirchner del poder en diciembre de 2007. La transmisión de la franja presidencial para su esposa, Cristina Fernández de Kirchner, en un escenario socio/económico/político más favorable, abrió camino para la elaboración de un marco regulatorio verdaderamente democrático para las comunicaciones: la Ley de Servicios de Comunicación Audiovisuales, sancionada en 2009.

¿Pero será que la nueva ley produjo reflejos en la transmisión de la señal de Telesur en Argentina?, ¿pueden ser observados resultados concretos en este sentido? Estas cuestiones fueron tratadas en otra ocasión (Mendes, 2012). 


\section{Bibliografía}

Albornoz, L. A. \& Hernández, P. (2009). La radiodifusión en Argentina entre 1995 y 1999: concentración, desnacionalización y ausencia de control público. En G. Mastrini (Ed.), Mucho ruido, pocas leyes (pp. 257-286). Buenos Aires, Argentina: La Crujía.

Arribá, S. (2009). El peronismo y la política de radiodifusión (19461955). En G. Mastrini, (Ed.), Mucho ruido, pocas leyes (pp. 71100). Buenos Aires, Argentina: La Crujía.

Augusti, M. S. \& Mastrini, G. (2009). Radio, economía y política entre 1920 y 1945: de los pioneros a las cadenas. En G. Mastrini (Ed.), Mucho ruido, pocas leyes (pp. 29-52). Buenos Aires, Argentina: La Crujía. Baladrón, M. (2009). La radiodifusión argentina después de la crisis de 2001: la política de comunicación del gobierno de transición de Eduardo Duhalde. En G. Mastrini, (Ed.), Mucho ruido, pocas leyes. (2a. ed.). Buenos Aires; Argentina: La Crujía.

Becerra, M. (2010). Las noticias van al mercado: etapas de la intermediación de lo público en la historia de los medios en la Argentina. Bicentenario de la Argentina. Bernal, Argentina: Universidad Nacional de Quilmes.

Becerra, M. \& Mastrini, G. (2009). Los dueños de la palabra. Buenos Aires, Argentina: Prometeo Libros.

Beltrán, L. R. (1976). Políticas nacionales de comunicación en América Latina: los primeros pasos. Nueva Sociedad, 25, 4-34.

Busso, N. \& Jaimes, D. (2011). La cocina de la Ley. Buenos Aires, Argentina: Farco Foro Argentino de Radios Comunitarias.

Califano, B. (2007). Medios y políticas de comunicación en Argentina bajo el gobierno de Néstor Kichner (2003-2007). Tesina de licenciatura, Carrera de Ciencias de la Comunicación, Facultad de Ciencias Sociales, Universidad de Buenos Aires, Argentina.

Coutinho, C. N. (Ed.). (2011). O leitor de Gramsci. Río de Janeiro, Brasil: Civilização Brasileira.

Cruz, J. M. (2004). ¿Qué es clientelismo? Algunas claves para comprender la política en los países en vías de consolidación democrática. Revista Estudios Sociales, 7, 123-142.

Esteban, E. (21 de noviembre sw 2011). A Telesur na Argentina. Entrevista concedida a G. S. Mendes, Buenos Aires, Argentina. 
Flores, R. C. (Ed.). (2005). Construyendo el Alba: Nuestro Norte es el Sur. Caracas: Parlamento Latinoamericano.

Hallin, D. \& Papathanassopoulos, S. (2002). Political clientelism and the media. Media, Culture \& Society, 24, 175-195. Recuperado el 10 de junio de 2011 de http://mcs.sagepub.com/cgi/content/abstract/24/2/175

Jambeiro, O. (2000). Regulando a TV: uma visão comparativa no Mercosul. Salvador, Brasil: Edufba.

Leiva, M. T. (2009). Fin de milenio: concentración, continuidad y control. Una mirada sobre las políticas de radiodifusión del gobierno de Fernando De la Rúa. En G. Mastrini (Ed.), Mucho ruido, pocas leyes (pp. 287-308). Buenos Aires, Argentina: La Crujía.

Ley 22.285. (1980). Recuperado el 20 de diciembre de 2011 de http:// www.catedras.fsoc.uba.ar/mastrini/legislacion/22285.pdf

Marino, S. (2007). Neoliberalismo, comunicación y políticas públicas: el caso de la televisión por cable en Argentina entre 1989 y 2001. Tesis de maestría en Comunicación y Cultura, Facultad de Ciencias Sociales, Universidad de Buenos Aires, Argentina.

Marino, S. \& Postolski, G. (2009) Relaciones peligrosas: los medios y la dictadura, entre el control, la censura y los negocios. En G. Mastrini, (Ed.), Mucho ruido, pocas leyes (pp. 155-184). Buenos Aires, Argentina: La Crujía.

Mastrini, G. \& Marino, S. (2008). Al final del periodo: los límites del progresismo. Políticas de Comunicación en Argentina durante el gobierno de Néstor Kirchner. Eco-pós, 11, 78-95. Recuperado el 21 de junio de 2011 de http://www.pos.eco.ufrj.br/ojs-2.2.2/index.php?jo urnal $=$ revista $\&$ page $=$ article $\&$ op $=$ viewFile $\&$ path []$=12 \&$ path []$=111$.

Mastrini, G. \& Mastman, M. (1995). ¿Desregulación o rerregulación?: de la derrota de las políticas a las políticas de la derrota. Ponencia presentada en la I Jornada de Jóvenes Investigadores en Comunicación. Buenos Aires, Argentina. Recuperado el 10 de agosto de 2011 de http://www.catedras.fsoc.uba.ar/mastrini/textos.htm.

Mendes, G. (2012). No descompasso da Lei de Meios: disputa pela hegemonia e acesso a Telesur na Argentina. Estudos em Comunicação, $11,251-273$. 
Moraes, D. (2011). Vozes abertas da América Latina. Río de Janeiro, Brasil: Mauad X/Faperj.

Murdock, G. (1991). Redrawing the map of the communication industries: Concentration and ownership in the era of privatization. En M. Ferguson, Public communication. The new imperatives, future directions for media research. Londres, Inglaterra: Sage.

Oszlak, O. \& O’ Donnell, G. (1995). Estado y políticas estatales en América Latina: hacia una estrategia de investigación. Redes, 2, 99-128. Recuperado el 11 de junio de 2011 de http:/www.bdp. org.ar/facultad/catedras/cp/analisispp/Oszlak\%20y\%200\%20Donnell\%20bib.pdf

Postolsky, G. (2010). Continuidades, desplazamientos y transformaciones en las políticas de comunicación en Argentina. En S. Sel, Políticas de comunicación en el capitalismo contemporáneo. Buenos Aires, Argentina: CLACSO.

Presidentes Chávez y Kirchner suscribieron acuerdos de cooperación e integración. (1 de febrero de 2005). Minci. Recuperado el 11 de noviembre de 2011 de http://www.minci.gob.ve/noticias_-_prensa/28/7288/presidentes_chavez_y.html

Rossi, D. (2009). La radiodifusión entre 1990-1995: exacerbación del modelo privado-comercial. En G. Mastrini (Ed.), Mucho ruido, pocas leyes. Buenos Aires, Argentina: La Crujía.

Fecha de recepción: 28/02/12. Aceptación: 19/06/12. 